\title{
Gait Variability among Healthy Adults: Low and High Stride-to-Stride Variability Are Both a Reflection of Gait Stability
}

\author{
Olivier Beauchet ${ }^{a} \quad$ Gilles Allali $^{b} \quad$ Cédric Annweiler $^{\mathrm{a}} \quad$ Stephanie Bridenbaugh $^{\mathrm{d}}$ \\ Frederic Assal $^{\mathrm{b}}$ Reto W. Kressig ${ }^{\mathrm{d}}$ François R. Herrmann ${ }^{\mathrm{c}}$ \\ aDepartment of Internal Medicine and Geriatrics, Angers University Hospital, UPRES EA 2646, University of Angers, \\ UNAM, France; Departments of ${ }^{\mathrm{b}}$ Neurology and ${ }^{\mathrm{c}}$ Rehabilitation and Geriatrics, Geneva University Hospital and \\ University of Geneva, Geneva, and d Department of Geriatrics, Basel University Hospital, Basel, Switzerland
}

\section{Key Words}

Stride-to-stride variability $\cdot$ Gait stability $\cdot$ Healthy adults

\begin{abstract}
Background: It has been suggested that high stride-tostride variability (STV) is a reflection of gait instability. However, both low and high STV has been shown in fallers and in nonfallers; therefore, the interpretation of STV of spatiotemporal gait parameters remains difficult. Thus, we sought to characterize and compare STV of spatial and temporal stride parameters among young and older healthy adults, and to determine the extent to which opposite results in STV could provide similar implications in terms of gait stability. Methods: Mean values of coefficients of variation of spatiotemporal gait parameters were collected from 30 young adults (14 men and 16 women; mean age $28.1 \pm 6.0$ years) and 33 older adults ( 2 men and 31 women; mean age $74.4 \pm 7.1$ years) walking at self-chosen normal walking speed over a GAITRite ${ }^{\circledR}$ System. Results: An age-related increase in STV was only observed with stride width $(p=0.012)$, whereas increased stride length and stance time variability in older adults were related to decreased walking speed $(p=0.006$ and $p=0.018$ ). In addition, both low and high STV was found in both groups of subjects and the highest value was ob-
\end{abstract}

served for stride width $(p<0.001)$. Conclusion: The two main implications of the present results are that decreased walking speed should be taken into account when exploring age-related effects on gait variability, and that both low and high spatiotemporal STV may reflect gait stability in healthy adults.

Copyright $\odot 2009$ S. Karger AG, Basel

\section{Introduction}

The assessment of stride-to-stride variability (STV) is central in the study of gait instability [1-3]. High stride time [2] and stride length variability [3] have separately been identified as fall predictors, whereas low variability in both these parameters has been associated with safe gait $[4,5]$. These data suggest that high STV is a reflection of gait instability [6]. Yet both low and high STV has been observed in fallers and in nonfallers [2, 3, 7-9], making the interpretation of STV difficult.

It is well known that healthy older adults devote more attention to gait control than young adults, which partly explains an age-related increase in STV $[10,11]$. However, few studies investigated the effect of potential confounders such as height, gender and walking speed $[4,5,7]$

\section{KARGER}

Fax +4161306 1234

E-Mail karger@karger.ch

www.karger.com (c) 2009 S. Karger AG, Basel

0304-324X/09/0556-0702\$26.00/0

Accessible online at:

www.karger.com/ger
Olivier Beauchet, $\mathrm{MD}$, PhD

Department of Geriatrics, Angers University Hospital

4 , rue Larrey

FR-49933 Angers Cedex 9 (France)

Tel. +33 24135 4725, Fax +33 24135 4894, E-Mail olbeauchet@chu-angers.fr 
when evaluating age-related changes in STV. It is therefore unclear whether increased STV is caused by age, confounders or both.

The aim of this study was (1) to characterize and compare the variability of spatial and temporal stride parameters among young and older healthy adults in analyzing the effects of potential confounders, and (2) to determine the extent to which opposite STV results could have similar implications in terms of gait stability.

\section{Methods}

Thirty young adults (14 men and 16 women; mean age $28.1 \pm$ 6.0 years; mean height $172.1 \pm 9.5 \mathrm{~cm})$ and 33 older adults $(2$ men and 31 women; mean age $74.4 \pm 7.1$ years; mean height $157.7 \pm$ $29.1 \mathrm{~cm}$ ) were recruited from the Department of Rehabilitation and Geriatrics of the Geneva University Hospitals. The disproportionate number of men versus women in the group of older adults is likely due to the higher prevalence of women in the geriatric population and may also be explained in part by our observation that older women tend to show greater interest in health issues and express more concern regarding falls than older men, and were thus more motivated to participate in the study. Informed consent was obtained. The participants were healthy and had no history of falls. The study was conducted in accordance with the ethical standards set forth in the Declaration of Helsinki (1983).

Gait parameters were collected with the GAITRite ${ }^{\circledR}$ System (GAITRite Gold; CIR Systems, USA) [8], a 10-meter-long walkway with integrated pressure sensors. Sensors are located every $1.27 \mathrm{~cm}$ over an active surface area of $7.32 \times 0.61 \mathrm{~m}$, giving a total of 27,648 sensors. Data from the mechanical pressure-activated sensors are collected by a series of on-board processors and transferred to a computer via an interface cable. The GAITRite software immediately transforms the raw data into spatiotemporal gait parameters. Automatically calculated mean values and coefficients of variation, i.e. $\mathrm{CoV}=[(\mathrm{SD} / \mathrm{mean}) \times 100]$, for the following gait parameters were evaluated in this study: stride time (i.e., the time elapsed between the first contacts of 2 consecutive footfalls of the same foot expressed in milliseconds), stride length (i.e., the distance between 2 consecutive footfalls of the same foot expressed in centimeters), stance time (i.e., the time elapsed between the first contacts and the last contact of 2 consecutive footfalls of the same foot expressed in percentages), swing time (i.e., the time elapsed between the last contact of current footfall to the first contact of the next footfall of the same foot expressed in percentages), and stride width (i.e., the distance from midline midpoints of 2 footfalls of the opposite foot).

The walking trials were performed according to the guidelines for spatiotemporal gait analysis [12]. A trained evaluator gave standardized verbal instructions regarding the test procedure, along with a visual demonstration of the walking test. To familiarize participants with the GAITRite system, each participant performed 1 practice walk before the recording. In order to measure steady-state gait, each walk trial was $12 \mathrm{~m}$ long to allow completion of at least 2 gait cycles before and after walking across the active measuring electronic surface area. Each participant per- formed 1 walk trial at her or his self-chosen, normal walking speed. The number of measured strides for each participant ranged from 6 to 12 .

Spatiotemporal stride measurements were summarized using means and standard deviations. The normality of the distribution of the parameters was verified with skewness and kurtosis tests before and after applying the usual transformations to normalize non-Gaussian variables. Firstly, the paired t test or Fisher's exact test was used to compare the subjects' baseline characteristics, as appropriate. Secondly, a comparison based on a balanced repeated-measures analysis of variance (ANOVA) was performed to evaluate the impact of age on the $\mathrm{CoV}$ of spatiotemporal stride parameters while adjusting for height, gender and walking speed without interaction terms. Thirdly, comparisons between the $\mathrm{CoV}$ of spatiotemporal stride parameters were performed using a repeated-measures ANOVA. $\mathrm{p}<0.05$ was considered statistically significant. All statistics were calculated using the Stata Statistical Software, version 9.2.

\section{Results}

There was a greater proportion of men in the group of young adults than in the group of old adults $[53.3 \%(\mathrm{n}=$ $16)$ vs. $6.1 \%(\mathrm{n}=2), \mathrm{p}<0.001$, respectively]. Young and old adults had similar weights $(64.9 \pm 2.4$ vs. $65.1 \pm 2.8$ $\mathrm{kg}, \mathrm{p}=0.966)$; old adults were shorter $(172.1 \pm 9.5 \mathrm{vs}$. $157.7 \pm 29.1 \mathrm{~cm}, \mathrm{p}=0.010)$ and walked slower $(137.6 \pm$ 3.4 vs. $114.9 \pm 3.5 \mathrm{~cm} / \mathrm{s}, \mathrm{p}<0.001)$. The mean values and standard deviations of spatiotemporal gait parameters for both groups of subjects are summarized in table 1. As shown in table 2, decreased walking speed was associated with higher values of the $\mathrm{CoV}$ of stride length and stance time in old adults compared to young adults $(\mathrm{p}=0.006$ and $p=0.018$ ), whereas only the impact of age explained the high gait variability of stride width $(\mathrm{p}=0.012)$. There was no significant difference between the two groups of subjects regarding the other gait parameters. As presented in figure 1, comparisons between the $\mathrm{CoV}$ of stride parameters showed that the $\mathrm{CoV}$ of stride time was lower than for all the other parameters $(p<0.001)$, except for stride length $(\mathrm{p}=0.764)$. Furthermore, $\mathrm{CoV}$ of stride length, stance time and swing time were significantly lower than the CoV of stride width $(\mathrm{p}<0.001)$.

\section{Discussion}

Our results showed that an age-related increase in STV was only observed with stride width, whereas increased stride length and stance time variability in older adults were related to slower walking speed. In addition, both low and high STV was found among both groups of 
Table 1. Mean values and standard deviations, along with minimum, maximum and range values of the CoV of spatiotemporal gait parameters $(n=63)$

\begin{tabular}{lccc}
\hline Stride parameters & Young subjects $(\mathrm{n}=30)$ & Old subjects $(\mathrm{n}=33)$ & All $(\mathrm{n}=63)$ \\
\hline Length, \% & $1.5 \pm 0.8(0.5 ; 3.4 ; 3.0)$ & $2.3 \pm 1.2(0.5 ; 5.2 ; 4.7)$ & $1.9 \pm 1.1(0.5 ; 5.2 ; 4.7)$ \\
Stride time, \% & $1.6 \pm 0.6(0.8 ; 3.1 ; 2.3)$ & $2.1 \pm 1.3(0.8 ; 6.1 ; 5.3)$ & $1.9 \pm 1.1(0.8 ; 6.1 ; 5.3)$ \\
Swing time, \% & $3.8 \pm 1.1(1.8 ; 6.0 ; 4.2)$ & $4.3 \pm 2.0(1.3 ; 10.5 ; 9.2)$ & $4.0 \pm 1.7(1.3 ; 10.5 ; 9.2)$ \\
Stance time, \% & $2.6 \pm 0.8(0.9 ; 3.9 ; 3.0)$ & $3.5 \pm 1.8(1.5 ; 8.4 ; 6.9)$ & $3.0 \pm 1.5(0.9 ; 8.4 ; 7.5)$ \\
Width, \% & $18.0 \pm 13.1(4.4 ; 66.4 ; 61.9)$ & $21.9 \pm 10.3(3.0 ; 47.2 ; 44.2)$ & $20.1 \pm 11.8(3.0 ; 66.4 ; 63.4)$ \\
\hline
\end{tabular}

Figures shown in parentheses are minimum, maximum and range.

Table 2. $\mathrm{p}$ value of ANOVA with a repeated-measures design estimating the effects of age on the $\mathrm{CoV}$ of gait parameters, adjusted for height, gender and walking speed

\begin{tabular}{llllll}
\hline $\begin{array}{l}\text { Stride } \\
\text { parameters }^{\mathrm{a}}\end{array}$ & \multicolumn{2}{l}{ Effect $^{\mathrm{b}}$} & & \multicolumn{2}{c}{$\mathrm{R}^{2}$} \\
\cline { 2 - 5 } & age & height & gender & walking speed & \\
\hline Length, \% & 0.407 & 0.729 & 0.637 & $\mathbf{0 . 0 0 6}$ & 0.22 \\
Time, \% & 0.510 & 0.306 & 0.103 & 0.113 & 0.11 \\
Swing time, \% & 0.717 & 0.060 & 0.327 & 0.075 & 0.11 \\
Stance time, \% & 0.091 & 0.269 & 0.050 & $\mathbf{0 . 0 1 8}$ & 0.22 \\
Width, \% & $\mathbf{0 . 0 1 2}$ & 0.301 & 0.188 & 0.884 & 0.04 \\
\hline
\end{tabular}

Significant $\mathrm{p}$ values $(\mathrm{p}<0.05)$ are indicated in bold.

${ }^{a}$ Normalized by taking the logarithmic transformation.

${ }^{b} \mathrm{p}$ value based on ANOVA with a repeated-measures design estimating the effects of age (coded as a binary variable; young adult $=0$ and old adult $=1$ ) on $\mathrm{CoV}$ of gait parameters, adjusted for height and gender (coded as a binary variable; male $=0$ and female $=$ 1) and walking speed $(137.6 \pm 3.4 \mathrm{~cm} / \mathrm{s}$ for young adults and $114.9 \pm 3.5 \mathrm{~cm} / \mathrm{s}$ for old adults). subjects. The highest value of STV was observed for stride width.

We demonstrated that older adults presented with higher STV than young adults; however, only a significant age-related effect was reported for stride width. Owings and Grabiner [13] reported similar results. Because step width variability allowed for the correct categorization of gait in old and younger adults in their study, they suggested that this parameter was the most sensitive descriptor of locomotion in healthy older adults. Our results corroborate this suggestion as the peak value of STV of stride width was observed in healthy older adults. Increased stride width variability has also been reported in older adults who had fallen. Brach et al. [7] showed that among older adults who walked with a gait speed greater than $1.0 \mathrm{~m} / \mathrm{s}$, fallers had significantly higher stride width variability than nonfallers $(28.8 \pm 29.1$ vs. $19.6 \pm 16.6$ with $\mathrm{p}=0.02$ ). In contrast, for subjects who walked slow- er than $1.0 \mathrm{~m} / \mathrm{s}$ there was no significant difference between fallers and nonfallers $(15.6 \pm 15.9$ vs. $15.7 \pm 7.7$ with $\mathrm{p}=0.95$ ). The authors concluded that extreme step width variability (either too much or too little) was associated with falls. The conclusion should be mitigated because the authors only showed that high step width variability was significantly related with fall when subjects walked above $1.0 \mathrm{~m} / \mathrm{s}$ and not under. The confounder is probably walking speed. Subjects who walked slowly (i.e., less than $1 \mathrm{~m} / \mathrm{s}$ ) regardless of their status (faller/nonfaller), had lower step width variability than those who walked faster than $1 \mathrm{~m} / \mathrm{s}$. In our study we did not find an effect of gait speed on stride width variability, probably because our subjects walked faster than $1 \mathrm{~m} / \mathrm{s}$. In addition, we report that higher variability values for stride length and stance time in older adults were related to slower walking speed rather than age. This result is in accordance with previous data which showed that increased 
Fig. 1. Box plot of the CoV of gait parameters $(n=63)$. $p$ value significant $(<0.014)$ based on the Bonferroni test calculated with a repeated-measures ANOVA.

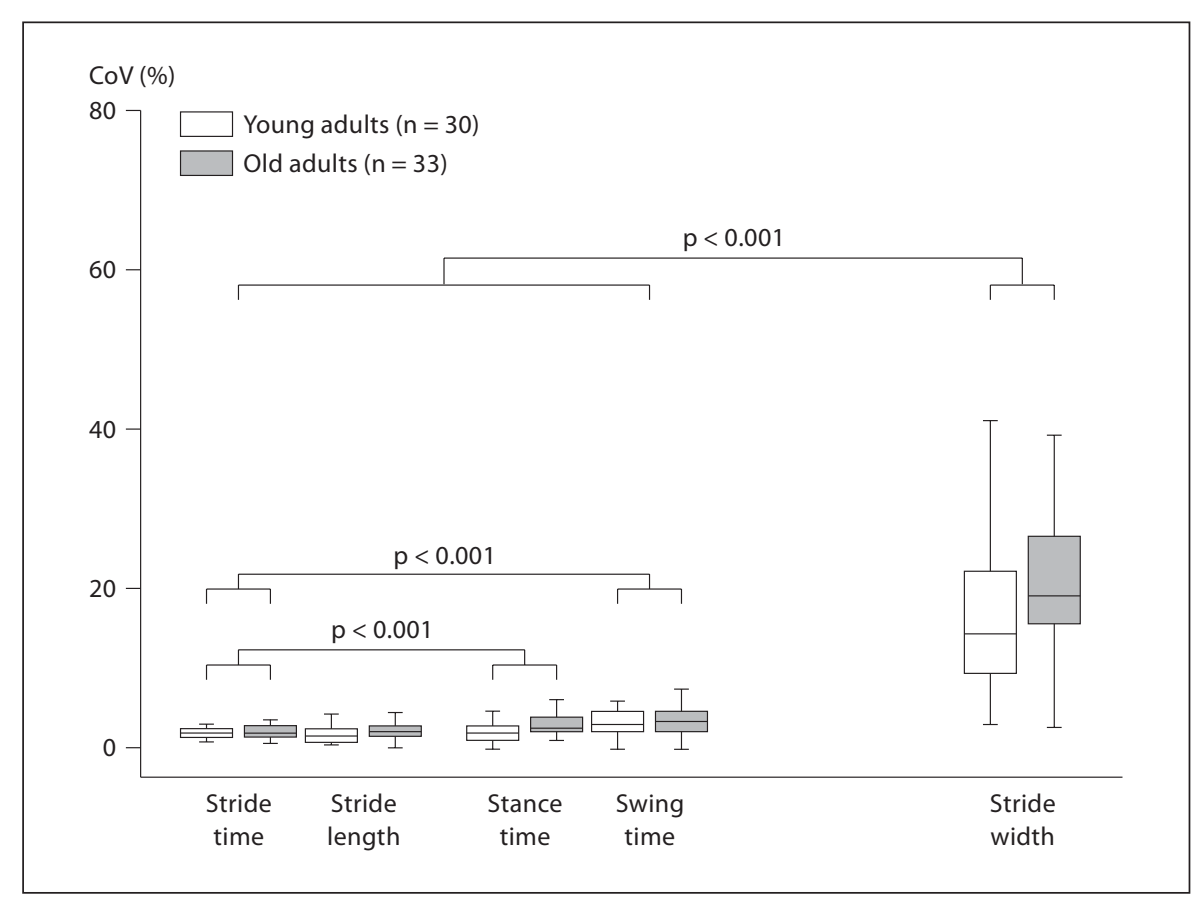

stride time variability was related to slower walking speed $[4,5,14]$.

Similar to our study results, Gabell et al. [9] reported that both low and high variability characterized safe gait in healthy adults. The apparent controversy over the general assumption that variability and stability are negatively correlated may be explained by gait control. In terms of motor control, low variability reflects an automatic process requiring minimal attention [1], whereas high variability is related to major attention involvement [11]. Dual-task-related gait changes, which are used to study the involvement of attention in gait control $[4,5]$, have highlighted the fact that the control of spatiotemporal stride parameters may differ from one parameter to another. For instance, it was shown that healthy young adults devoted attention to balance control under dual task conditions [15], whereas the control of the walkingrelated rhythmic stepping mechanism did not change [4]. Both stride time and stride length variability are related to the control of the rhythmic stepping mechanism [3-5]. Low variability values reflect the reliability of limb movements and the automated regular rhythmic feature of gait and are associated with safe gait $[1,4,5]$. In contrast, gait parameters related to balance control such as stride width have high variability $[3,7,9]$. From a biomechanical viewpoint, variability is necessary to maintain balance $[3,9]$. It is a reflection of the ability to adapt limb movement while walking, leading to greater stability [6, 9], and suggests that higher variability in stride width compared to stride time or stride length is required to maintain a safe gait in healthy adults. High variability of stride parameters should therefore also be considered as a marker of adaptability to the walking environment.

In conclusion, the two main implications of our findings are that decreased walking speed should be considered when exploring age-related effects on gait variability, and that both low and high variability of spatiotemporal parameters may reflect gait stability in healthy adults. These results emphasize the importance of cautiously interpreting gait variability when evaluating gait stability.

\section{Acknowledgment}

We are grateful to the participants for their cooperation.

\begin{tabular}{|c|c|}
\hline References & $\begin{array}{l}1 \text { Newell KM, Corcos DM: Issues in variability } \\
\text { and motor control; in Newell KM, Corcos } \\
\text { DM (eds): Variability and Motor Control. } \\
\text { Champaign, Human Kinetics, 1993, pp 1- } \\
12 \text {. } \\
2 \text { Hausdorff JM, Rios DA, Eldelberg HK: Gait } \\
\text { variability and fall risk in community-living } \\
\text { older adults: a 1-year prospective study. Arch } \\
\text { Phys Med Rehabil 2001;82:1050-1056. }\end{array}$ \\
\hline
\end{tabular}


3 Maki BE: Gait changes in older adults: predictors of falls or indicators of fear? J Am Geriatr Soc 1997;45:313-320.

-4 Dubost V, Kressig RW, Gonthier R, Herrmann FR, Aminian K, Najafi B, Beauchet O: Relationships between dual-task related changes in stride velocity and stride time variability in healthy older adults. Hum Mov Sci 2006;25:372-382.

5 Beauchet O, Dubost V, Herrmann FR, Kressig RW: Stride-to-stride variability while backward counting among healthy young adults. J Neuroeng Rehabil 2005;2:26.

6 Beauchet O, Allali G, Berrut G, Dubost V: Is low lower-limb kinematic variability always an index of stability? Gait Posture 2007;26: 327-328.
7 Brach JS, Berlin JE, VanSwearingen JM, Newman AB, Studenski SA: Too much or too little step width variability is associated with a fall history in older persons who walk at or near normal gait speed. J Neuroeng Rehabil 2005;2:21.

8 Bilney B, Morris M, Webster K: Concurrent related validity of the GAITRite ${ }^{\circledR}$ walkway system for quantification of the spatial and temporal parameters of gait. Gait Posture 2003; 17:68-74.

$\checkmark 9$ Gabell A, Nayak US: The effect of age on variability in gait. J Gerontol 1984;39:662666.

10 Beauchet O, Najafi B, Dubost V, Aminian K, Mourey F, Kressig RW: Age-related decline of gait control under a dual-task condition. J Am Geriatr Soc 2003;51:1187-1188.

11 Woollacott M, Shumway-Cook A: Attention and the control of posture and gait: a review of an emerging area of research. Gait Posture 2002;16:1-14.
12 Kressig RW, Beauchet O; European GAITRite Network Group: Guidelines for clinical applications of spatio-temporal gait analysis in older adults. Aging Clin Exp Res 2006;18: 174-176.

13 Owings TM, Grabiner MD: Step width variability, but not step length variability or step time variability, discriminates gait of healthy young and older adults during treadmill locomotion. J Biomech 2004;37:935-938.

14 Heiderscheit BC: Movement variability as a clinical measure for locomotion. J Applied Biomech 2000;16:419-427.

15 Gage WH, Sleik RJ, Polych MA, McKenzie NC, Brown LA: The allocation of attention during locomotion is altered by anxiety. Exp Brain Res 2003;150:385-384.

\section{Erratum}

In the article by Aoyagi et al: Habitual physical activity and physical fitness in older Japanese adults: the Nakonojo study. Gerontology 2009;55:523-531, an error occurred in table 1.

Please note: the value for 'Peak handgrip force' under the column 'Men' should now read $334 \pm 61$. 